\title{
Relacionamento interorganizacional na integração ensino-serviço de enfermagem na atenção primária à saúde
}

\author{
Inter-organizational relationship in the integration teaching-nursing service at the primary health care \\ Relaciones interinstitucionales en la integración enseñanza-servicio de enfermería \\ en la atención primaria de salud
}

\section{Selma Regina de Andrade', Astrid Eggert Boehs', Bruna Coelho", Isabel Maria Schmitt", Carlos Gabriel Eggert Boehs"I}

' Universidade Federal de Santa Catarina, Departamento de Enfermagem, Programa de Pós-Graduação em Enfermagem. Florianópolis-SC, Brasil.

"Universidade Federal de Santa Catarina, Curso de Graduação em Enfermagem. Florianópolis-SC, Brasil.

II' Universidade Positivo, Programa de Pós-Graduação em Administração. Curitiba-PR, Brasil.

\author{
Submissão: 10-09-2013 Aprovação: 07-06-2014
}

\section{RESUMO}

O estudo objetivou caracterizar as fases do relacionamento interorganizacional na integração ensino-serviço do exercício da Enfermagem, no âmbito operacional da atenção primária à saúde em um município catarinense. Adotou-se a abordagem qualitativa em um estudo de caso da cooperação entre duas organizações. Foram entrevistados oito enfermeiros docentes e oito enfermeiros assistenciais. Realizou-se análise de conteúdo com os resultados demonstrando uma série de elementos quanto às fases da interação (negociação, compromisso e execução de atividades), bem como à variabilidade de seu conteúdo ao longo do tempo. Conclui-se que a interação no nível operacional caracteriza-se por dinâmicas ao longo dos ciclos de relacionamento que abrangem usualmente o semestre letivo, com produção de novas negociações e compromissos para o seguinte.

Descritores: Atenção Primária à Saúde; Sistema Único de Saúde; Educação em Enfermagem; Integração Docente-Assistencial.

\begin{abstract}
This study aimed to characterize the stages of the inter-organizational relationships between educational and caring aspects of Nursing, operating in the context of primary health care in a municipality of Santa Catarina, Brazil. The qualitative approach of the case study was used by deliberately selecting the cooperation between two organizations. Eight teaching nurses and eight assistant nurses were interviewed. The data were submitted to content analysis, and the results demonstrated a number of elements in the phases of interaction (negotiation, commitment and execution of activities), as well as the variability of their content over time. It was concluded that the interaction, at an operational level, is characterized by dynamics that happen during relationship cycles, usually spanning through the school-semester, producing new negotiations and commitments for the following semester.
\end{abstract}

Key words: Primary Health Care; Unified Health System; Nursing Education; Integration Teaching Care.

\section{RESUMEN}

El estudio tuvo como objetivo caracterizar las fases de las relaciones inter-organizacionales en el ejercicio de la integración docente-asistencial de Enfermería, que operan en el contexto de la atención primaria de salud en un municipio de Santa Catarina. Adoptó-se un enfoque cualitativo, de estudio de caso de la cooperación entre ambas organizaciones. Se entrevistó a ocho profesores de enfermería y ocho enfermeros asistenciales. El análisis de contenido de los datos recogidos ha demostrado una serie de elementos como las fases de interacción (negociación, el compromiso y la ejecución de actividades), así como la variabilidad de su contenido en el tiempo. Se concluye que la interacción, en nivel operativo, se caracteriza por la dinámica al largo de los ciclos de la relación, que por lo general cubren el semestre, con la producción de nuevas negociaciones y compromisos para el siguiente.

Palabras clave: Atención Primaria de Salud; Sistema Único de Salud; Educación en Enfermería; Integración Enseñanza-Servicio. 


\section{INTRODUÇÃO}

A integração ensino-serviço é um dos eixos norteadores do Programa Nacional de Reorientação da Formação Profissional em Saúde (Pró-Saúde) do Ministério da Saúde ${ }^{(1)}$. Pressupõe a construção de práticas pedagógicas em saúde, considerando os estudantes como sujeitos de sua própria formação, e objetiva a transformação das práticas profissionais e da própria organização do trabalho.

O Curso de Graduação em Enfermagem (CGE) da Universidade Federal de Santa Catarina (UFSC) foi contemplado com o Projeto Pró-Saúde I, em parceria com a Secretaria Municipal de Saúde de Florianópolis (SMSF). O principal objetivo do Pró-Saúde I consiste em promover a articulação entre as instituições de ensino superior e as de prestação de serviço público, para potencializar respostas às necessidades de formação de recursos humanos, produção do conhecimento e prestação de serviços no Sistema Único de Saúde (SUS) ${ }^{(1)}$.

Para a execução do Pró-Saúde foi necessária intensa cooperação entre a SMSF e o CGE/UFSC, em três âmbitos de interação: no nível estratégico - entre coordenadores e dirigentes da UFSC e da SMSF; em um nível de articulação - entre professores e profissionais de saúde envolvidos com a gestão de recursos e coordenação dos centros de saúde; e, por fim, em um nível operacional - por meio da interação entre os enfermeiros que atuam efetivamente no dia a dia da assistência e os docentes integrantes das disciplinas que realizam as atividades práticas e estágios.

Na última década, a literatura sobre Estudos Organizacionais tem discutido o fenômeno das relações interorganizacionais ${ }^{(2)}$. No contexto nacional, foram estudadas relações de cooperação e confiança entre instituições de uma rede privada de servi$\operatorname{ços}^{(3)}$; os processos de comunicação entre organizações ${ }^{(4)}$ e de cooperação entre instituições de pesquisa do setor público ${ }^{(5-6)}$.

As relações de cooperação interorganizacional também são abordadas na literatura relacionada à pesquisa em saúde. Estudo bibliográfico ${ }^{(7)}$ identificou 110 artigos cuja temática eram as parcerias entre serviços de saúde e instituições de ensino e pesquisa em enfermagem. No entanto, tais estudos ainda apresentam caráter pouco aprofundado e diversos deles mencionam os resultados alcançados com as parcerias, sem explicitar os critérios formais adotados para tais avaliações ${ }^{(7)}$.

No contexto da saúde pública, discute-se a relevância das parcerias multisetoriais para o desenvolvimento da saúde das populações para promoção da saúde ${ }^{(8)}$. Na Enfermagem, a cooperação interorganizacional vem sendo estudada principalmente no âmbito da formação no ensino superior ${ }^{(9-11)}$.

O presente artigo retrata o terceiro momento de uma pesquisa sobre a integração ensino-serviço e aborda as fases de relacionamento interorganizacional no âmbito da atenção primária à saúde. Está inserido em um contexto processual de aprendizagem da profissão, em cooperação com os serviços públicos de saúde, e alinha-se aos estudos que enfocam as parcerias que sustentam tais atividades.

A perspectiva de análise empregada vincula-se ao referencial teórico das relações interorganizacionais ${ }^{(12)}$, no qual as relações de cooperação são compreendidas a partir do processo de construção de sentidos e na dinâmica das fases dos relacionamentos: negociação, comprometimento e execução de atividades. A relevância das relações de cooperação decorre não apenas de aspectos estruturais, mas também processuais (ações e atividades técnicas e administrativas), que determinam as condições do relacionamento entre as organizações parceiras. Ademais, o processo de desenvolvimento da cooperação interorganizacional é compreendido de forma cíclica, simultânea em alguns casos, e com etapas reincidentes. O caráter cíclico não se deve à estabilidade alcançada no relacionamento, mas à manutenção de equilíbrio entre processos formais e informais de interação.

A dimensão conceitual da fase de negociação ${ }^{(12)}$ é caracterizada pela existência de processos formais (registrados de forma documental) e informais (comunicações verbais) de interação que constroem a compreensão que cada parceiro passa a ter para sua contraparte. Nessa fase, os participantes da relação vivenciam incertezas e apresentam expectativas associadas à parceria, a natureza do papel de cada um, à confiabilidade no parceiro, aos direitos e os deveres a serem considerados na transação e à possível eficiência e equidade da transação. $\mathrm{O}$ processo de barganha e a construção do sentido da interação ocorrem por meio da comunicação. A superação das incertezas, a confiabilidade, os direitos e os deveres, bem como a eficiência e a equidade decorrem da percepção dos negociadores.

$\mathrm{Na}$ fase de comprometimento ${ }^{(12)}$ ocorre o ajustamento das vontades das partes, com acordos sobre as obrigações e as regras das ações futuras no relacionamento. Os termos e a estrutura de governança são estabelecidos, seja por meio de processos formais, na modalidade de contratos relacionais, ou informais, caracterizados por acordos psicológicos. Por acordos psicológicos entende-se a definição das expectativas das partes a respeito do que cada um irá dar e receber no relacionamento.

A execução(12) é a etapa em que os comprometimentos e as regras são levados a efeito. Inicialmente, os comportamentos baseados em designações formais reduzem a incerteza. Quando comprometimentos são executados, a previsibilidade do relacionamento aumenta, o que caracteriza a adoção de processos formais. A partir de uma série de interações, as pessoas envolvidas tornam-se mais conhecidas umas das outras e podem se basear de forma crescente em processos informais, por meio de relacionamentos interpessoais, em vez de relacionamentos baseados em papéis formais. Na prática, a execução será identificada por meio de atividades decorrentes das designações formais dos acordos definidos entre as partes da aliança (contratos, atas de reuniões, cronogramas), bem como de entrevistas para identificar as interações dos indivíduos, as atividades realizadas e a existência de conflitos do cotidiano.

Diante do exposto, a presente investigação foi orientada pela seguinte pergunta de pesquisa: Considerando as diretrizes do Projeto Pró-Saúde - Enfermagem e o referencial das relações interorganizacionais, como se caracteriza o relacionamento das instituições envolvidas na integração ensino-serviço na atenção primária à saúde? Seu objetivo é caracterizar as fases de relacionamento interorganizacional da integração ensino-serviço no âmbito operacional da atenção primária à saúde em um município catarinense. 


\section{MÉTODO}

Trata-se de um estudo de caso único, de abordagem qualitativa, em que a cooperação entre duas organizações foi estudada em profundidade. A pesquisa foi realizada no município de Florianópolis, Santa Catarina, junto a docentes do Curso de Graduação em Enfermagem da Universidade Federal de Santa Catarina (CGE/UFSC), envolvidos em atividades teórico-práticas, e enfermeiros da Secretaria Municipal de Saúde de Florianópolis (SMSF), lotados em Centros de Saúde (CS) onde se desenvolve o projeto Pró-Saúde.

A seleção das organizações foi do tipo intencional, em busca da compreensão de um fenômeno particular, não corriqueiro - a relação de cooperação entre duas instituições. Participaram da pesquisa profissionais enfermeiros, docentes e assistenciais, que atuam de forma direta no ensino e na assistência das duas instituições.

No CGE/UFSC, os critérios de inclusão foram: docentes efetivos e substitutos que atuavam ou haviam atuado desde o início da execução do projeto em março de 2007 nos CS em atividades de docência com alunos de graduação de enfermagem. Foram excluídos os professores admitidos há menos de seis meses do período da entrevista. Na SMSF, os critérios de inclusão foram: enfermeiros e coordenadores dos CS que realizavam atividades de ensino com estudantes de enfermagem desde a implantação do projeto. Foram excluídos os enfermeiros sem envolvimento direto com os estudantes de enfermagem e aqueles contratados há menos de seis meses do período da entrevista.

A coleta de dados foi efetuada pelos autores do projeto e por bolsistas devidamente capacitados, sendo entrevistados em cada CS um docente e um enfermeiro, após autorização e consentimento. Os CS foram escolhidos entre aqueles que iniciaram atividades docentes desde 2007. Os oito selecionados correspondem a $50 \%$ das unidades onde atuavam ou já haviam atuado acadêmicos de enfermagem, distribuídos pelos cinco distritos do município de Florianópolis: Norte, Leste, Sul, Centro e Continente. O instrumento para coleta de dados foi um formulário com perguntas aplicadas por meio de entrevista semiestruturada agendada com antecedência e duração média de 30 minutos.

Os dados foram submetidos análise de conteúdo. Foram adotados indicadores qualitativos na análise de conteúdo, com a técnica de categorização(13). O software NVivo $8.0^{\circ}$ foi usado para dar suporte à organização e à análise dos dados. Os dados foram interpretados sob a perspectiva das fases de relacionamento na interação interorganizacional, conforme o referencial adotado ${ }^{(12)}$.

Este estudo está vinculado ao macroprojeto "Caracterização das fases do relacionamento e formas de controle da cooperação entre o CGE/UFSC e SMSF no projeto Pró-Saúde I - Enfermagem", financiado pelo Pró-Saúde I - carta acordo UFSC/MS/OPAS. Foi submetido e aprovado pelo Comitê de Ética em Pesquisa da UFSC n. 2186/11. Os entrevistados concordaram em participar da pesquisa após a leitura e a assinatura do Termo de Consentimento Livre e Esclarecido.

\section{RESULTADOS}

No referencial adotado ${ }^{(12)}$, a divisão do histórico de um relacionamento interorganizacional, em fases distintas é um modo de facilitar a compreensão dos processos envolvidos no fenômeno. Esse passa por uma desconstrução analítica para facilitar sua compreensão em termos de etapas, conteúdo, conflitos, comportamentos e percepções dos atores envolvidos.

Negociação, comprometimento e execução de atividades de ensino em cenário de prática

A análise do relacionamento entre as duas organizações permitiu identificar elementos das fases da interação e a variabilidade de seu conteúdo ao longo do tempo. Na sequência são identificadas situações associadas às características das fases de relacionamento interorganizacional ${ }^{(12)}$. Acrescenta-se ao processo analógico a identificação de um esquema gráfico (Quadro 1) de como os relatos possibilitam a identificação do histórico sequencial das etapas do relacionamento.

\section{A negociação no nível de articulação (Comitê Gestor): NA-N0}

Alguns docentes mencionaram reuniões do Comitê Gestor de Atenção Básica, formado pelos dirigentes do CGE e do Departamento de Ensino da SMSF, que se reúne mensalmente e tem poder de decisão sobre a escolha de CS e de orientadores, discussão de eventuais problemas e conflitos na relação (fase identificável no Quadro 1: NA-N0). Também fizeram referência à realização semestral de um fórum ampliado de integração ensino-serviço, com participação de enfermeiras e docentes. Portanto, antes da interação no nível operacional, há outras esferas de interação e articulação do processo de negociação.

Ocorrem normalmente atividades como a reunião dos docentes envolvidos com atividades teóricas e práticas nas unidades de saúde com as enfermeiras dessas unidades de saúde municipais. Ela acontece no período entre um e outro semestre ou logo na primeira semana do semestre e tem como objetivo retomar a avaliação do que nós vivemos no semestre anterior e o planejamento inicial do próximo. (D6)

\section{A negociação no nível operacional (Centros de Saúde): NO-N1}

No nível operacional, objeto desta análise, o contato primeiramente é formalizado pelo coordenador da disciplina para os coordenadores dos CS, informando o início das atividades práticas e dos estágios, os professores responsáveis e o número de alunos. Após essa comunicação, os docentes que irão atuar diretamente na unidade buscam acordos com os enfermeiros para iniciar as atividades. Este contato é feito por meio de comunicados eletrônicos, ligações telefônicas ou reuniões presenciais.

Os docentes relatam que normalmente é realizada uma reunião presencial no CS, em que há uma conversa inicial entre os parceiros e exposição do que será desenvolvido no semestre, buscando conciliar as atividades de ensino com as de assistência, tais como consultas de enfermagem e atividades educativas. Mas também reconhecem que nem sempre isto ocorre. 
Quadro 1 - Fases do relacionamento interorganizacional entre o Curso de Graduação em Enfermagem e o Departamento de Ensino da Secretaria de Saúde, Pró-Saúde Enfermagem. Florianópolis-SC, 2007-2012

\begin{tabular}{|c|c|c|c|c|}
\hline \multirow{2}{*}{$\begin{array}{l}\text { Relacionamento } \\
\text { interorganizacional }\end{array}$} & \multicolumn{2}{|c|}{ Antes do início das atividades semestrais } & \multicolumn{2}{|c|}{$\begin{array}{l}\text { Início e decorrer das atividades de estágio e } \\
\text { atividades práticas no semestre }\end{array}$} \\
\hline & $\begin{array}{l}\text { Fase de } \\
\text { relacionamento }\end{array}$ & Conteúdo & $\begin{array}{l}\text { Fase de } \\
\text { relacionamento }\end{array}$ & Conteúdo \\
\hline $\begin{array}{c}\text { *Nível de } \\
\text { Articulação (NA) } \\
\text { (Comitê Gestor) }\end{array}$ & $\begin{array}{c}\text { Negociação } \\
\text { (N0) } \\
\text { (inicial) }\end{array}$ & $\begin{array}{l}\text { Avaliação de resultados; } \\
\text { Definição de novos locais } \\
\text { de estágio; } \\
\text { Planejamento do semestre; } \\
\text { Designação de enfermeiro } \\
\text { para supervisão }\end{array}$ & & \\
\hline \multirow[t]{3}{*}{$\begin{array}{l}\text { Nível Operacional } \\
\text { (NO) } \\
\text { (Centros de Saúde) }\end{array}$} & $\begin{array}{l}\text { Negociação1 } \\
\text { (N1) }\end{array}$ & $\begin{array}{l}\text { Contato formal do docente } \\
\text { da disciplina com os } \\
\text { coordenadores locais dos } \\
\text { Centros de Saúde; Contatos } \\
\text { prévios e realização de } \\
\text { reuniões; } \\
\text { Apresentação das } \\
\text { atividades a serem } \\
\text { desenvolvidas; } \\
\text { Apresentação dos } \\
\text { professores. }\end{array}$ & $\begin{array}{l}\text { Execução1 } \\
\quad(\mathrm{E} 1)\end{array}$ & 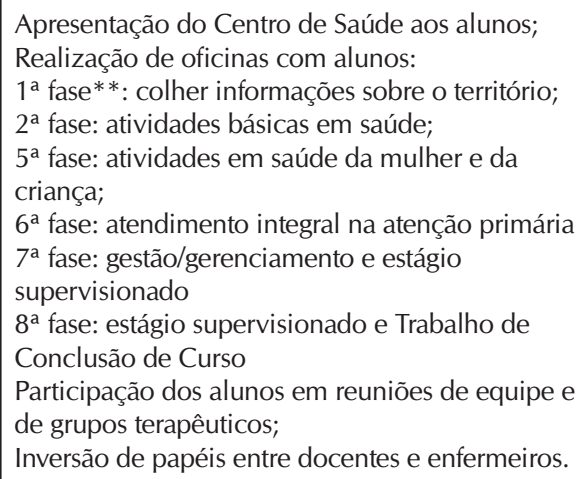 \\
\hline & $\begin{array}{l}\text { Comprometimento1 } \\
\text { (C1) }\end{array}$ & $\begin{array}{l}\text { Reuniões com apresentação } \\
\text { e confirmação de } \\
\text { cronogramas. }\end{array}$ & $\begin{array}{l}\text { Negociação2 } \\
\text { (N2) }\end{array}$ & $\begin{array}{l}\text { Renegociação de atividades; } \\
\text { Renegociação de cronogramas (por demanda } \\
\text { do Centro de Saúde ou do Curso). }\end{array}$ \\
\hline & & & $\begin{array}{l}\text { Comprometimento } \\
2 \text { (C2) }\end{array}$ & $\begin{array}{l}\text { Confirmação informal de novas atividades e } \\
\text { novos cronogramas, com a finalização das } \\
\text { atividades do semestre nos CS (apresentação } \\
\text { de resultados; relatórios; confraternizações; } \\
\text { feedback). }\end{array}$ \\
\hline
\end{tabular}

* Apesar de não constituir o foco deste estudo, o Nível de Articulação (NA) integra o objeto mais amplo da pesquisa e foi citado pelos entrevistados. ** O CGE/UFSC denomina "fases" os semestres letivos nos quais o aluno está inserido.

Uma entrevistada relatou que em um determinado semestre não foram realizados esses contatos iniciais e as tratativas sobre o assunto ocorreram apenas por meio de comunicação eletrônica, o que teria acarretado um transtorno no decorrer do semestre:

[...] a gente viu que estava tendo muito contratempo, porque faltou realmente sentar e negociar. Então no semestre seguinte antes de iniciar, foi feito uma reunião com o enfermeiro coordenador da unidade e foram discutidas como seriam as atividades. (D1)

Outra mencionou o comprometimento das disciplinas em encaminhar os novos professores substitutos para o CS antes do início das atividades dos alunos.

Se há algum professor facilitador novo, a gente faz o possível para que ele vá antes, pelo menos umas duas a três semanas, sem os alunos, para conhecer o campo, se familiarizar com a rotina, para que possa se integrar e não chegar tão verde quanto chegam os alunos naquela unidade. (D3)
Relatos semelhantes foram observados entre os enfermeiros dos CS, que também informaram que os contatos prévios ocorrem por e-mail ou telefone e uma reunião é agendada no CS.

\section{O compromisso no nível operacional (Centros de Saúde): NO-C1}

Segundo os enfermeiros e docentes, nas reuniões preliminares que ocorrem nos CS, discutem-se quais atividades irão ocorrer, segundo o cronograma geralmente preestabelecido, de acordo com cada disciplina.

A execução no nível operacional e seus desdobramentos em novas negociações e novos compromissos no relacionamento ensino-serviço: NO E1

No início da execução das atividades, há esforços tanto dos docentes quanto dos enfermeiros para que a equipe local conheça os alunos.

Quando se entra com os alunos, a primeira semana é para eles reconhecerem a unidade, conversarem com os 
profissionais, conversarem com os usuários. Se naquela semana tem alguma reunião de equipe, a gente já se apresenta. E fazíamos sempre uma reunião, uma oficina com os agentes comunitários de saúde, não só para apresentar os alunos, como também colher informações sobre o território. (D3)

As apresentações formais aumentam as possibilidades de integração dos alunos, abrindo caminho para relações interpessoais informais e possibilitando a execução de atividades junto aos usuários ${ }^{(2,12)}$.

Sobre as atividades realizadas pelos acadêmicos, os docentes mencionaram que são desenvolvidas de acordo com as disciplinas que estão cursando. Na disciplina do primeiro semestre, o aluno vai ao CS para conhecer a comunidade e realizar o processo de territorialização; no segundo, são desenvolvidos projetos de educação em saúde. No quinto semestre, os acadêmicos realizam atividades voltadas para a saúde da mulher e da criança. Ao longo do sexto semestre, atuam em saúde mental voltada para a comunidade e desenvolvem as atribuições que competem ao enfermeiro da atenção primária, com exceção da atividade de gestão, que é abordada apenas no sétimo semestre. Também é comum no oitavo semestre os estudantes realizarem o trabalho de conclusão de curso no CS.

As respostas de grande parte dos docentes estavam de acordo com as disciplinas em que atuavam. Já os enfermeiros, como recebem alunos das diferentes disciplinas, responderam de forma mais abrangente:

Acho que tudo! Vamos dizer assim, na $1^{\text {a }}$ fase, $2^{\text {a }}$ fase, vão usar mais os agentes comunitários para conhecer como é o território. [...] Na $6^{\text {a }}$ fase, [fazem] praticamente tudo que o enfermeiro faz, desde consulta de puericultura, consulta à gestante, consultas de urgência no acolhimento. (E6)

Nos relatos tanto de docentes como de enfermeiros constatou-se que é frequente a participação dos alunos nas reuniões do Conselho Local de Saúde, nas reuniões de equipe da ESF e nas reuniões gerais do CS. Participam também de reuniões educativas com usuários. Um enfermeiro mencionou a contribuição dos alunos quando se inserem nos grupos de educação em saúde:

A gente tem o grupo de diabetes que já existe há vários anos e chega uma hora que a gente pensa: "O que eu vou falar nesse grupo?". Quando vêm os alunos, eles são criativos, trazem coisas diferentes. É bom para os pacientes, é uma experiência para eles e uma renovação para a gente. (E3)

Sobre a forma de trabalhar em conjunto, os enfermeiros relataram que nas atividades práticas das disciplinas os docentes assumem com os alunos as atividades dos enfermeiros. Em outras ocasiões, os alunos acompanham o trabalho dos enfermeiros, por exemplo, nas consultas de enfermagem. Nos estágios supervisionados, que ocorrem nos semestres finais do curso, os enfermeiros, na condição de supervisores diretos, organizam-se para proporcionar maior experiência aos alunos.
A gente procura fazer um rodízio entre os enfermeiros para que eles [os alunos da $8^{a}$ fase] vejam várias condutas diferentes trabalhando em conjunto, porque isso é muito importante. Ninguém pensa igual, cada um tem o seu jeitinho ou alguma coisinha diferente que coloca em seu trabalho. (E4)

As renegociações durante a execução das atividades: E1 N2

Na fase de execução das atividades práticas e dos estágios, o cronograma pré-estabelecido exige novas negociações e novos compromissos nas decisões que são tomadas para o desenvolvimento da parceria de docentes, alunos e equipe local. Estas renegociações ocorrem com mais intensidade nas disciplinas em que os alunos têm maior tempo de permanência dentro do CS.

A $6^{a}$ fase, que é uma fase em que se está aqui o semestre inteiro, a gente fica negociando e renegociando o tempo todo, conforme as possibilidades dos alunos, do campo, as coisas novas que surgem. Quando são atividades mais pontuais, como na $1^{a}$ e a $2^{a}$, não muda muito, você negocia no momento inicial e aquilo que foi negociado permanece! (E1)

As razões para essas negociações constantes, segundo os docentes, são necessidades manifestadas pela equipe local, como, por exemplo, a necessidade de suprir a ausência de um profissional ou realizar busca ativa para um aprendizado específico. Os enfermeiros corroboram tal afirmação, alegando que, pelas características da atenção primária, a demanda de usuários é imprevisível.

Dada a forma como são realizadas as novas negociações, tanto docentes como enfermeiros concordam que tais processos ocorrem continuamente ao longo do semestre, em contatos informais e, em alguns casos, com maior formalidade, por meio de reuniões.

\section{Os novos compromissos durante a execução das ativida- des: E1 C2}

A finalização das atividades do semestre é bastante diversificada, depende das disciplinas e do tempo compartilhado pelas equipes nos CS. Quando o envolvimento é grande, é usual haver uma reunião em que os alunos mostram as atividades realizadas ao longo de semestre, seguida de uma confraternização.

Geralmente é uma reunião seguida de uma confraternização. Primeiro eles mostram o que foi alcançado e depois encerram com uma confraternização. (D1)

Além disso, também há uma preocupação para a manutenção das relações, procurando-se manter relações cordiais, conforme relata uma docente:

Eu e a professora substituta sempre deixamos uma mensagem de Natal e final de ano [...] eu passo lá pra desejar um Feliz Natal. (D5) 
Houve discrepância sobre a afirmação de alguns docentes acerca da entrega de relatório escrito para o CS e a afirmação dos enfermeiros de que conhecem apenas o relato oral dos alunos. Percebe-se que a finalização, mesmo bastante diversa, com reuniões ou confraternizações, coincide com a preocupação e as tratativas sobre o retorno no semestre seguinte, servindo como processo de avaliação do semestre que se encerra e o planejamento e discussão das atividades do semestre subsequente, renovando-se o ciclo da relação interorganizacional.

Constatou-se interferência do nível de articulação existente entre o Comitê Gestor de Atenção Básica, constituído pelo Departamento de Ensino da SMSF e a Coordenação CGE, que se reúne com a presença de coordenadores das disciplinas que atuam nos CS, em uma fase prévia à interação com os enfermeiros envolvidos no nível operacional. As interferências estão no âmbito dos cenários da prática, como, por exemplo, na escolha de supervisoras locais, campos de estágio e número de estudantes por local.

\section{DISCUSSÃO}

No primeiro momento de interação, em que o docente vai até a unidade conversar e negociar com o coordenador e os enfermeiros do CS, ocorrem discussões prévias do relacionamento, conhece-se o parceiro e determina-se a importância de um para o outro. Nesse momento há a construção da percepção sobre a confiabilidade e a eficiência do parceiro. Existe um contato inicial antes da chegada dos acadêmicos na unidade de saúde, com discussão prévia do relacionamento, negociação de atividades e acordos, como o estabelecimento e a submissão ao CS do cronograma definido pelos docentes.

$\mathrm{Na}$ fase de negociação da relação interorganizacional ${ }^{(12)}$, há definição dos papéis de cada parte e entram em jogo as diferentes expectativas: no caso de docentes e alunos, quanto ao processo de ensino e aprendizagem e, da parte dos enfermeiros, quanto ao processo de cuidar e à organização dos serviços, ou seja, como as atividades de estágio irão impactar suas tarefas cotidianas. As falhas ou a inexistência dessa etapa preliminar repercutem tanto no processo de ensinar e aprender quanto no desenvolvimento das atividades no CS e, por consequência, no aproveitamento da parceria.

A fase de negociação resulta em comprometimento entre as partes, expresso objetivamente por meio do resultado do cronograma. Os relatos, no entanto, indicam que o cronograma geralmente é apenas informado aos enfermeiros assistenciais, tendo sido negociado em reuniões ocorridas no outros níveis de interação, ou seja, dentro das disciplinas na universidade, com comunicação ao Departamento de Ensino da SMSF. Ainda que seja repassado pelos docentes, o cronograma instituído, mesmo sem a negociação com os profissionais do CS, constitui um acordo e resulta na criação de expectativas de ambas as partes de que as atividades seguirão tais definições.

Um estudo sobre a relação entre uma instituição de ensino e a rede pública de saúde na formação em Medicina revelou que há maior interferência da universidade sobre instituição de saúde do que o contrário. Além disso, gestores e trabalhadores dos serviços não participam da discussão do currículo ou dos conteúdos das disciplinas e pouco da construção das metodologias $^{(14)}$.

Um dos fenômenos identificados foi a troca de papéis entre docentes e profissionais de saúde, uma oportunidade de entendimento da cultura e do contexto entre as partes na relação interorganizacional, proporcionando um sentido comum na parceria ${ }^{(2)}$.

O estágio supervisionado é destacado como uma experiência importante na articulação ensino-serviço, pois permite a criação de vínculos com a população e o desenvolvimento mais contínuo das atividades, fortalecendo a autonomia dos estudantes ${ }^{(9)}$. O processo de supervisão dos estudantes por enfermeiras dos serviços abre um caminho mais profícuo na integração ensino-serviço, criando oportunidades para que tenham papel ativo e colaborando diretamente para a formação. Está de acordo com o que a literatura sugere em outras áreas da saúde, no sentido de estabelecer uma articulação mais estreita de modo a tornar o usuário e a saúde da população os verdadeiros focos da atenção de docentes, alunos e equipe, não somente o ensino ${ }^{(15-16)}$.

Nas disciplinas que mantêm os alunos mais tempo dentro dos CS, os processos formais de apresentação e execução do cronograma de ensino vão sendo substituídos por processos informais e dinâmicos, à medida que docentes e alunos vão se tornando mais conhecidos da equipe e dos usuários e os papéis de quem faz o ensino e o cuidado vão se mesclando. As incertezas presentes no início da parceria tendem a diminuir quando os mesmos docentes retornam a cada semestre e encontram a mesma equipe na unidade de saúde.

Estudo que investigou a interação entre organizações portuguesas de serviços de saúde e as de ensino superior na área da Enfermagem ${ }^{(10)}$ concluiu que a cooperação assenta-se não somente em relações formais e informais, mas também em valores simbólicos e ideológicos ligados à profissão, além de relações de confiança e amizade que condicionam seu funcionamento.

Nos relacionamentos interorganizacionais, a plena conexão entre os parceiros faz-se de forma progressiva, ocorrendo apenas após determinado tempo de relacionamento entre os interessados $^{(3)}$. Com a consolidação das relações, amplia-se também o nível de compreensão e confiança, assim como a comunicação informal, tornando mais simples lidar com as incertezas que aparecem ao longo da aliança ${ }^{(2-3,7)}$. Ao contrário, a substituição de docentes ou membros das equipes dos CS constitui um fator restritivo ao processo de interação e forte potencial para o aumento de incertezas, quebra de confiança e ocorrência de conflitos.

Em síntese, no nível operacional é possível constatar que a ocorrência de reuniões preliminares ao início das atividades demonstra o processo de negociação e comprometimento, resultando usualmente em cronogramas de trabalho. Na prática, as fases podem ocorrer simultaneamente e sua ausência pode estar associada à necessidade de novas negociações ou ao surgimento de eventuais conflitos. Assim, durante o período em que ocorrem as atividades com os alunos, há recorrência de novos processos de negociação de atividades e cronogramas, bem como de novas repactuações de compromissos.

Corroborando os resultados do estudo que tratou da caracterização da formação dos profissionais de saúde na atenção primária ${ }^{(17)}$, identificam-se potencialidades e desafios na 
parceria entre a universidade e a secretaria de saúde, especialmente com relação a uma formação voltada para a implementação dos princípios do SUS e a troca de experiências de caráter multiprofissional e interdisciplinar. Além disso, outro estudo $^{(9)}$ enfatiza que há reconhecimento pelos profissionais de serviço da possibilidade de renovação de conhecimentos e, em consequência, das práticas, quando há inserção do estudante no cenário real da atenção primária.

Os relatos indicam ainda que, segundo a matriz curricular do CGE, cada disciplina corresponde a um nível específico de aprendizado, realiza diferentes atividades e, portanto, diferentes processos de interação com os profissionais de saúde e usuários. Tal evidência implica diferentes tipos de negociação, com maior ou menor necessidade de formalização.

A associação feita com base nas atividades de conclusão de semestre constitui fator-chave para compreender a renovação dos ciclos de interação. Os relatos evidenciam divergências entre as diferentes disciplinas, nos diferentes CS, quanto à realização de reuniões, apresentação de relatórios e eventuais confraternizações. Nos semestres subsequentes, a continuidade das mesmas equipes de docentes e profissionais que já se conhecem também é apontada como um aspecto positivo que facilita a negociação, a realização de atividades e a assunção de novos compromissos.

Quanto à interferência do nível central, estudo(11) sobre o tema demonstrou que níveis decisórios de efetivação do relacionamento interorganizacional desenvolvem de forma cíclica relações de compromisso, negociação e execução, desde a formalização da proposta pelo nível estratégico, até sua implantação pelo Comitê Gestor.

\section{CONSIDERAÇÕES FINAIS}

O foco deste estudo é a interação, no nível operacional, dos agentes envolvidos em um projeto de cooperação voltado para as atividades acadêmicas de estudantes de enfermagem nos CS. A desconstrução em etapas do processo interativo de relacionamento entre agentes das duas instituições possibilitou compreender as dinâmicas ao longo dos ciclos de relacionamento que usualmente abrangem o semestre letivo. Produziu-se assim uma reflexão analítica das atividades cooperadas, relacionando seu conteúdos e os eventuais conflitos com a forma como são estruturadas as dinâmicas dos relacionamentos. Essa é possivelmente a maior contribuição que esse processo pode proporcionar.

O estudo possibilitou ainda refletir sobre outro fenômeno trazido à tona pelos entrevistados: a cessão deliberada de espaços físicos e de ação dos profissionais das unidades de saúde para docentes e alunos. O relato de que docentes desenvolvem as atividades das enfermeiras com o intuito de promover o aprendizado dos alunos e a atuação das enfermeiras como instrutores, supervisores e avaliadores constitui evidência do grau de compromisso e envolvimento que esses agentes assumem.

Novos processos investigativos, de abordagem qualitativa ou quantitativa, nesta e noutras realidades de cooperação entre a Universidade e os Serviços Municipais de Saúde, podem buscar identificar qual a relação entre o nível de detalhamento das interações nas fases de negociação prévia entre professores e profissionais de saúde e as possibilidades de conflito nas fases posteriores da interação.

\section{REFERÊNCIAS}

1. Ministério da Saúde (BR). Programa Nacional de Reorientação da Formação Profissional em Saúde - Pró-Saúde: objetivos, implementação e desenvolvimento potencial. Brasília (DF): Ministério da Saúde; 2007.

2. Vlaar PWL, Van den Bosch FAJ, Volberda HW. Coping with problems of understanding in interorganizational relationships: using formalization as a means to make sense. Organization Studies [Internet] 2006 [cited 2013 Jul 10];27(11):1617-38. Available from: http://oss.sagepub.com/cgi/content/abstract/27/11/1617

3. Pirani SL, Cunha CR. A formação da confiança: um estudo no pool da Unibraspe. Rev Adm UFSM [Internet] 2010 [acesso em 28 de maio de 2014];3(3):375-92. Disponível em http://www.redalyc.org/articulo.oa?id=273419412006

4. Cruz EMK, Segatto AP. Processos de comunicação em cooperações tecnológicas universidade-empresa: estudos de caso em universidades federais do Paraná. RAC. Rev Adm Contemp [Internet]. 2009 [acesso em 16 de junho de 2013];13(3):430-49. Disponível em http://www.scielo. br/pdf/rac/v13n3/v13n3a06.pdf

5. Dossa AA, Segatto AP. Pesquisas cooperativas entre universidades e institutos públicos no setor agropecuário brasileiro: um estudo na Embrapa. Rev Adm Pública [Internet].
2010 [acesso em 02 Jul 2013];44(6):1327-52. Disponível em: http://www.scielo.br/scielo.php?pid=S0034-7 $6122010000600004 \&$ script $=$ sci_arttext

6. Ferreira Júnior I, Segatto AP. Institutos de pesquisa do Paraná e o uso de seus recursos no desenvolvimento de relações cooperativas com empresas. Rev Gestão USP. 2009;16(2):1-15.

7. Beal JA. Academic-service partnerships in Nursing: an integrative review. Nurs Res Pract [Internet]. 2012 [cited 2013 jul 23];28(6):327-32. Available from: http://www. readcube.com/articles/10.1155/2012/501564

8. Woulfe J, Oliver TR, Zahner SJ, Siemering KQ. Multisector partnerships in population health improvement. Prev Chronic Dis [Internet]. 2010 [cited 2013 jul 02];7(6). Available from: http://www.cdc.gov/pcd/issues/2010/ nov/10_0104.htm

9. Silva KL, Sena RR, Grillo MJC, Horta NC, Prado PMC. Educação em enfermagem e os desafios para a promoção de saúde. Rev Bras de Enferm [Internet]. 2009 [acesso em 16 agosto de 2013];62(1):86-91. Disponível em: http:// www.scielo.br/pdf/reben/v62n1/13.pdf

10. Arco $\mathrm{H}$, Silva $\mathrm{C}$. Dilemas das redes de cooperação interorganizacionais e a formação dos profissionais de saúde: 
o caso da enfermagem. In: VII Congresso Português de Sociologia; 2012; Porto, Brasil [acesso em 03 agosto de 2013]. Disponível em http://www.aps.pt/vii_congresso/ papers/finais/PAP0331_ed.pdf

11. Andrade SR, Boehs AE, Mattia D, Boehs CGE, Daussy MFS. Cooperação e relacionamento entre instituições de ensino e serviço de saúde: o pró-saúde enfermagem. Texto \&Contexto Enferm [Internet]. 2014 [acesso em 28 de maio de 2014];23(1)160-6. Disponível em http://www.scielo .br/scielo.php?script $=$ sci arttext\&pid $=$ S0104$-07072014000100160 \& \operatorname{lng}=$ pt\&nrm $=$ iso\&tlng $=p t$

12. Ring PS, Van de Ven AH. Developmental processes of cooperative interorganizational relationships. Academy Management Review. 1994;19(1):90-118.

13. Hsieh HF, Shannon SE. Three approaches to qualitative content analysis. Qual Health Res. 2005; 15(9):1277-88.

14. Azevedo BM, Ferigato S, Souza TP, Carvalho SR. A formação médica em debate: perspectivas a partir do encontro entre instituição de ensino e rede pública de saúde. Interface Comun Saúde Educ [Internet]. 2013 [acesso em 26 de agosto de 2013];17(44):187-200. Disponível em http://www.scielo.br/scielo.php?pid=S1414$-32832013000100015 \&$ script $=$ sci_arttext

15. Finkler M, Caetano JC, Ramos FRS. A Integração "ensino-serviço" no processo de mudança na formação profissional em odontologia. Interface Comun Saúde Educ [Internet]. 2011 [acesso em 26 de agosto de 2013];15(39):105370. Disponível em: http://www.scielo.br/scielo.php?pid $=$ S1414-32832011000400008\&script $=$ sci_arttext

16. Albuquerque VS, Gomes AP, Rezende CHA, Sampaio MX, Dias OV, Lugarinho RM. A integração ensino-serviço no contexto dos processos de mudança na formação superior dos profissionais de saúde. Rev Bras Educ Méd. 2008;32(3):356-62.

17. Cavalheiro MTP, Guimarães AL. Formação para o SUS e os desafios da integração ensino-serviço. Caderno FNEPAS. [Internet]. 2011 [acesso em 26 de agosto de 2013];1:1927. Disponível em: http://www.fnepas.org.br/artigos caderno/formacao_para_sus_desafios_integracao.pdf 